\title{
A Thought-Provoking Thesis on Swedish Trans-Specific Healthcare
}

Linander, Ida. 2018. "It was like I had to fit into a category": People with Trans Experiences Navigating Access to Trans-Specific Healthcare and Health. PhD diss. Umeå University: Department of Public Health and Clinical Medicine, Epidemiology and Global Health. (I5 I pages)

The AIM Of Ida Linander's (20I8, iv) $\mathrm{PhD}$ thesis is to analyze how "constructions of trans experiences and gender can affect trans-specific healthcare practices, experiences of navigating access to genderconfirming medical procedures, inhabitancy of different spaces and, ultimately, health." Linander aims at showing how gender constructions constitute people's experiences in and with the health sector, healthcare practices and trans health policies and guidelines, and affect which spaces feel safe/unsafe for trans persons. Who is evaluated as a "real" or "truly" gender dysphoric person, worthy of trans-specific healthcare, by whom, and on basis of what kind of criteria? How does a person with trans experiences navigate this terrain, and with what results and effects on the person's overall health? How are persons with trans experiences empowered or disempowered and affected by the constructions of gender, gender norms, and gender identity? Linander shows that in order to understand trans experiences, it is vital to look into the construction of gender as linear - stereotypical, binary and stable - in the medical evaluations of healthcare seekers, as well as in the first 
formal guidelines for trans-specific healthcare. Some care-seekers embrace the linear gender position, some negotiate it in order to obtain much-needed healthcare, while others resist the position altogether. A second construction, important to understanding care-seekers' experiences with trans-specific healthcare, as well as the guidelines for transspecific healthcare, is the construction of gender dysphoria as a mental health issue, to be evaluated and administered by mental healthcare professionals. This gate-keeping function construes care-seekers as "not competent enough to make decisions concerning access to genderconfirming medical procedures" (v).

Linander's method has been interviews with eighteen persons with trans experiences navigating access to trans-specific healthcare in Sweden. A second sub-study is a policy analysis of the guidelines for trans-specific healthcare, authored by the Swedish National Board of Health and Welfare in 2015, while the third sub-study looks into safe/ unsafe public and community spaces and how this relates to perceived health.

In Norway, we use(d) to say: "Look to Sweden." Sweden has six gender identity clinics (compared to Norway's one and only authorized team in Oslo), the trans healthcare is renowned, and specialized teams cooperate with individual healthcare providers (contrary to Norway). Sweden abolished forced sterilization earlier than Norway and those who underwent forced sterilization can apply for damage compensation. However, Linander's research exposes situations quite similar to those I observed in the first Norwegian research on trans people's living conditions and trans-specific health provisions (van der Ros 2013): long waiting time for care-seekers and slow processes; little selfdetermination concerning type of care; negotiating healthcare through strategic gender-conforming behavior proven to ensure access to transspecific medical procedures; regulatory gate-keeping power, through evaluations by mental health professionals, causing unhealthy dependency relations between care-seekers and healthcare providers; little or no support or follow-up, and lack of trans-specific health issues in the general healthcare sector. It is all so uncannily familiar. 
The thesis provides an interesting epistemological narrative; creative "snapshots" offer insights in the development of Linander's thinking around doing research with people with trans experiences, redirecting the thesis' aim to obtaining insights that can improve trans-specific healthcare. "I have been driven [...] with an aspiration for social change" (4), Linander writes. While starting out to theorize sex/gender, applying trans experiences in that endeavor, the author's ethical (and political?) conscience redirected the focus of the thesis toward looking into trans persons' experiences with trans healthcare and the contexts of such care, such as the gendered discourses, the power of health professionals, and the navigating strategies of trans people. Through the subjects' stories, Linander develops a transfeminist position, with an attention to gendered hierarchies (such as sex/gender, and binary/nonbinary) and to discriminatory practices based on gender identity and expression. An added virtue is that Linander, coming from the medical field, also situates the thesis within the critical public health tradition. Linander's choice of qualitative methods is unusual in this tradition: diverting from the so-called objective and disinterested science production, toward an engaged and situated knowledge production in order to better explore public health concerns for trans people and their experiences with public health.

I appreciate Linander's theoretical approach, combining discourse analysis with (queer) phenomenology, topping it by integrating Michel Foucault's power analysis and his concept of governmentality. The approach is ambitious and the application on trans experiences in and with the health sector is enlightening; a showcase for $\mathrm{PhD}$ students. To quote the author:

A queer phenomenological approach can contribute to important knowledge of how discourses are lived, embodied, and experienced by the participants. [...] [M]y empirical focus on the participants' experiences makes it possible to analyse and draw conclusions about how power and governing are experienced. (4I) 
One good example of this is the analysis of how time and temporality is used as a diagnostic tool and a governing technique, found at pages I05-6.

Of course, as a feminist trans and gender studies political science scholar, I applaud Linander's use of Carol Bacchi's "What is the problem represented to be" approach in the policy analysis of the guidelines for trans-specific healthcare. It is such a good tool to outline how problem construction leads to certain ways of problem solution. A "born-in-thewrong-body" definition of gender incongruence calls for other solutions than understanding gender incongruence as "assigned a wrong gender marker at birth" would. Not least, Bacchi's approach invites scholars to look for the silences, for what is left unproblematic is relevant here.

A short review cannot do justice to this thesis. Sharp analytical observations and theoretical interpretations should have been mentioned. My advice: Do read this thesis - it is an intellectual joy, a theoretical challenge, and it provides empirical insights in an important theme of our time, with implications and applications also beyond the specific issue.

JANNEKE VAN DER ROS INLAND NORWAY UNIVERSITY OF APPLIED SCIENCES

\section{REFERENCE}

Van der Ros, Janneke. 20I3. Alskens folk: Levekär, livssituasjon og livskvalitet for personer med kjønnidentitets-tematikk. Oslo: Likestillingssenteret . https://bufdir.no/bibliotek/Dokumentside/?docId=BUFoooor926 